Ege Tıp Dergisi / Ege Journal of Medicine 2015;54(3):114-119

\title{
Polis meslek yüksekokulu öğrencilerinde sigara kullanımına yönelik görüş ve tutumun değerlendirilmesi
}

Evaluation of opinions and attitudes of cigarette use in police vocational high school students

\author{
Görkem YARARBAŞ Demet HAVAÇELIĞì ATLAM
}

Ege Üniversitesi, Madde Bağımlılığı Toksikoloji ve İlaç Bilimleri Enstitüsü, İzmir, Türkiye

\section{Öz}

Amaç: Polislik mesleği, sigara kullanımı açısından riskli meslek grupları içerisinde yer almaktadır. Bu çalışmanın amacı, polis meslek yüksekokulu öğrencilerinin sigara kullanımının ve sigaraya ilişkin görüş ve tutumlarının araştırılmasıdır.

Gereç ve Yöntem: Araştırmada basit tesadüfi örneklem metodundan yararlanıldı. Anket, 810 kişilik evrenden 1 . ve 2. sınıflarında okuyan 294 öğrenciye sınıf ortamında uygulandı. Araştırmada, sigara kullanımı, sigara içme nedenleri, bırakma nedenleri ve sigara yasakları konusunda hazırlanan 10 soruluk anket formu kullanıldı.

Bulgular: Katılımcıların \%33.7'si sigara kullanıcısı olarak bulundu. Sigaraya başlama yaşı 7-19 arasında olup, haftalık paket kullanımı ortalama $4.4 \pm 2.8$ idi. Sigara kullanımı olan ve olmayanlar arasında sigara içme nedenleri ve sigaranın bırakılmasında profesyonel destek alınmasının gerekliliği konusunda anlamlı farklılık bulundu $(p<0.05)$. Sigaranın bırakılma nedenleri konusunda gruplar arasında anlamlı farklılık bulunmadı.

Sonuç: Araştırmada polis okulu öğrencilerinde bulunan sigara kullanım yaygınlığı (\%33.7) diğer üniversitelerin çalışmalarıyla paralellik göstermektedir. Literatürde yer alan çalışmalarla kıyaslandığında sigara içme oranlarının azaldığı görülmektedir. Çalışma, sigara içen ve içmeyen gruplar arasında sigara kullanımına yönelik düşünceler açısından belirgin farklııklar olduğunu ortaya koymaktadır.

Anahtar Sözcükler: Polis, sigara kullanımı, pasif içicilik, tütün düzenlemeleri.

\section{Abstract}

Aim: Police profession is located in occupational risk groups in terms of smoking consumption. The aim of this study is to investigate smoking habits and opinions and attitudes of cigarette use in police vocational high school students.

Materials and Methods: Simple random sample method was utilized in the research. The questionnaire was applied to 294 out of 810 students in their classrooms who were first and second year students. In this study, 10-question survey form consisted of cigarette use, reasons for smoking and cessation of smoking, and smoking bans.

Results: Current smokers were found as $33.7 \%$ of participants. Age to start smoking was between 7 and 19 , the

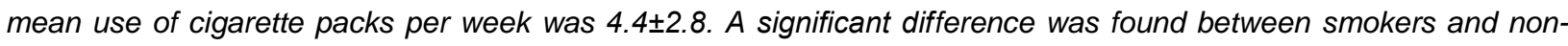
smokers in terms of reasons for smoking and necessity to take professional support for smoking cessation $(p<.05)$. There was no significant difference between two groups about reasons for cessation of smoking.

Conclusion: In this study, the smoking prevalence (33.7\%) in the police vocational high school students was found similar to other university students. It was observed that smoking rates were decreased when compared with studies in the literature. The results show that there are significant differences between smoking and non-smoking groups in terms of opinions about cigarette use.

Keywords: Police, cigarette use, passive smoking, regulation of tobacco.

\footnotetext{
Yazışma Adresi: Görkem YARARBAŞ

Ege Üniversitesi, Madde Bağımılıı̆ı, Toksikoloji ve İlaç Bilimleri

Enstitüsü, İzmir, Türkiye

Makalenin Geliş Tarihi: 08.03.2014 Kabul Tarihi: 23.06.2014
} 


\section{Giriş}

Dünya Sağlık Örgütü (DSÖ), sigarayı "dünyanın en hızlı yayılan ve en uzun süren salgını" olarak tanımlamaktadır (1). Gerek dünyada gerekse ülkemizde sigara içme alışkanlığı önemli bir halk sağlığı sorunu olarak ifade edilir (2). Ülkemizde düzenli tütün kullanıcıları, en çok 25-34 yaş grubu (\%34.9) ve 35-44 yaş grubunda (\%36.2) yer almaktadır. 15 yaş ve üstü bireylerin her gün veya ara sıra tütün ve tütün mamullerini kullanma oranı $\% 27$ 'dir (3).

Gelişmiş ülkelerde erişkinlerde sigara içme boyutunda bir azalma saptanırken, gelişmekte olan ülkelerde, gençlerde ve özellikle ergenlerde bu davranışın gittikçe yaygınlaştığı görülmektedir (4). Sigaraya, genellikle ergenlik döneminde merak, özen, gösteriş, taklit, büyüme veya özgürlük ifadesi olarak başlanır (5). Ergenlik dönemi, kimlik geliştirme süreci içinde bulunan ve yoğun içsel çatışmalar yaşanan bir dönemdir ve sigara, alkol ve maddelere başlama açısından riskli bir dönemdir (6). Özellikle erken yaşlarda sigara içmeye başlama ile bağımlılık riskinin arttığı bilinmektedir (7). Küresel Yetişkin Tütün Araştırması'na göre her gün sigara içenlerin \%39,3'ü "15-17" yaş grubunda sigarayı kullanmaya başlamıştır (8). Son yıllarda sigara içme yaşının gittikçe düştüğü görülmektedir. Dünya Sağlık Örgütü’nün 2008 yılı verilerine göre sigara içenlerin yaklaşık dörtte biri 10 yaşından önce ilk kez sigara ile tanışmaktadır (9). Özellikle risk altında olan grupların sigara ile tanışma yaşı gittikçe düşmektedir. Polisler üzerine yapılan araştırmalarda erken yaşta sigara kullanımı dikkat çekmektedir (10).

Polislik mesleği, sigara kullanımı açısından riskli meslek grupları içerisinde yer almaktadır. Mesleğin yarattığı stresin ve çalışma koşullarının etkisiyle sigara, aşırı alkol kullanımı ve sağlıksız yaşam stilleri, normal popülasyona göre daha yüksektir (11). Ülkemizde polisler üzerine yapılan araştırmalarda sigara kullanım oranının \%41-61 arasında değiştiği görülmektedir (10,12). Yapılan araştırmalar, polis okulu öğrencilerinin diğer üniversite öğrencilerine göre daha yüksek sigara kullanım oranına sahip olduğu göstermektedir (13-15). Bu araştırmada amaç, polis yüksekokulu öğrencilerinin sigara kullanım özelliklerinin ve sigaraya yönelik tutumların araştırılmasıdır.

\section{Gereç ve Yöntem}

Araştırma evrenini, İzmir'de, alanında tek olan Polis Meslek Yüksek Okulu öğrencileri oluşturmaktadır. Örneklemin hesaplanmasında, 810 kişilik öğrenci evreni için \%95 güven aralığı, \pm 0.05 sapma miktarıyla 261 kişilik örneklem sayısı; örneklemin en az \%32.2'lik kısmının çalışmaya alınması yeterli görülmüştür. Basit tesadüfi örneklem yönteminden yararlanılmıştır. Sınıf ortamında bulunan 294 kişiye uygulama gerçekleştirilmiştir. Bu sayı da örneklemin \%36.2'sini temsil etmektedir.
Çalışma kapsamında yaş, sigara kullanımı, masrafı, kullanım adedi, sigaraya başlama nedenleri, bırakma nedenleri, bırakmada profesyonel destek almanın gerekliliği ve sigara yasakları konusunda hazırlanan 10 soruluk anket formundan yararlanılmıştır. Bu form, literatürde yapılan çalışmalar ve sigara alanındaki deneyimlere göre hazırlanmıştır.

Uygulama, 2013 yılının Aralık ayında sınıf ortamında eğitmenler gözetiminde gerçekleştirilmiştir. Uygulamaya katılma gönüllülüğe dayalı olup katılımcılardan isimsoyad, öğrenci no vb. kişisel bilgiler alınmamıştır. Sigara kullanımına yönelik tutumların değerlendirilmesinde sigara kullanımı olan ve olmayan grup ayrımı yapılmıştır. Veriler, SPSS-18 istatistik programında analiz edilmiş ve analizlerde sıklıklara ilişkin frekans dağılımları ve sigara kullanımı olan ve olmayan gruplar arası farkın değişkenlerle ilişkisini değerlendirmek üzere Pearson kikare testleri kullanılmıştır. Anlamlılık düzeyi $p<0.05$ olarak kabul edilmiştir.

\section{Bulgular}

Yaşları 18-23 arasında değişen katılımcıların yaş ortalaması $19.3 \pm 1.16$ 'dır. Sigara kullanımı ile ilgili soruya yanıt veren 291 kişinin 98'i (\%33.7) sigara kullandığını, 193'ü (\%66.3) kullanmadığını beyan etti. Kullanımı olan 98 kişinin sigaraya başlama yaşları 7-19 arasında değişmektedir, en yaygın yaş grubu 16-19'dur \%61.2 (Tablo-1). Sigara içenlerde bir haftada tüketilen paket miktarı ortalama $4.4 \pm 2.8$ pakettir (min:1, maks: 25 ).

Tablo-1. Sigara Kullanımına Illişkin Bilgiler.

\begin{tabular}{|lcc|}
\hline Yaş Dağılımı & $\%$ & $\mathbf{n}$ \\
\hline 18 yaş & 29.4 & 86 \\
19 yaş & 32.1 & 94 \\
20 yaş & 22.5 & 66 \\
21 yaş & 11.9 & 35 \\
22 yaş ve üstü & 4.1 & 12 \\
\hline Sigara Kullanımı & & \\
\hline Evet & 33.7 & 98 \\
Hayır & 66.3 & 193 \\
\hline Sigaraya Başlama Yaşı (n=98) & \\
\hline 0-11 yaş & 6.1 & 6 \\
12-15 yaş & 32.7 & 32 \\
16-19 yaş & 61.2 & 60 \\
\hline Sigara Masrafı (aylık) & & \\
\hline 0-20 TL & 3.1 & 3 \\
20-60 TL & 15.3 & 15 \\
60-100 TL & 29.6 & 29 \\
100-140 TL & 26.5 & 26 \\
140 TL ve üstü & 25.5 & 25 \\
\hline
\end{tabular}

Araştırmaya katılanların sigara kullanımı ve yasakları konusundaki görüşleri de alındı. Bu doğrultuda sigara kullanımı olan ve olmayanlar olarak iki gruba ayrılarak değerlendirme yapıldı. Çalışmada, öğrencilerin "sigara 
kullanımının sizce en önemli nedeni nedir?" sorusuna ilişkin farklı görüşlere sahip oldukları saptandı $(p=0.0001)$. Sigaranın zaman geçirme, kilo kontrolü, arkadaşlar arasında ilgi çekmek gibi nedenleri birleştirilerek sosyal nedenler; rahatlatıcı etkisi ve içmeden yapmamak gibi nedenler de birleştirilerek bağımlıı̆a dayalı fiziksel nedenler olarak değerlendirildi. Sigara kullanımı olanlar ve olmayanlar arasında anlamlı farklılık bulundu $(p=0.0001)$. Sigara kullanımı olanların \%68.1'i, olmayanların \%41.9'u bağımlılığa bağlı fiziksel nedenleri belirtti (Tablo-2).

Araştırmada sigara kullanımı olan ve olmayan kişilerin, sigarayı bırakmanın nedenleri konusunda görüş ayrılıklarının olmadığını saptandı ( $p>$.05). Özellikle sağlık sorunları nedeniyle sigarayı bırakma, her iki grup açısından en geçerli neden (\%76.8) olarak vurgulandı. Aile ve çevre baskısının, ekonomik nedenlerin, sigara yasaklarının ve bunların dışındaki diğer nedenlerin sigarayı bırakmada etkili olduğu da bulunmuştur. Katılımcılar tarafından diğer nedenler olarak evlilik, sevdiği kişinin etkisi, bilinçlendirme çalışmaları, din ve vicdan gibi ifadeler de belirtilmiştir. Öğrencilerin \%64.9'u sigarayı bırakma konusunda profesyonel yardım (sigara bırakma polikliniği vb.) almak gerektiğini belirtmiştir. Bu durum, kullanımı olan ve olmayan açısından değerlendirildiğinde; sigara kullananların \%45.8'i, kullanmayanların \%74.7'si profesyonel yardım alınması gerektiğini ifade etmiştir ve her iki grubun görüşü arasında anlamlı farklılık bulunmuştur ( $p=0.0001)$ (Tablo-2).

Tablo-2. Sigara Kullanan ve Kullanmayanların Sigaraya İlişkin Görüşleri.

\begin{tabular}{|c|c|c|}
\hline Sigara içmenin en önemli nedeni nedir? & $\begin{array}{c}\text { Sigara Kullanan } \\
(\%)\end{array}$ & $\begin{array}{c}\text { Kullanmayan } \\
(\%)\end{array}$ \\
\hline Bağımlılığa bağlı nedenler ( İçmeden yapamamak, rahatlatıcı etkisi) & 68.1 & 41.9 \\
\hline \multirow{2}{*}{ Sosyal Nedenler (Kilo kontrolü, zaman geçirme, arkadaşlar arasında dikkat çekmek) } & 31.9 & 58.1 \\
\hline & \multicolumn{2}{|c|}{$\left(p=0.0001 ; x^{2}: 16.729 ; d f: 1\right)$} \\
\hline \multicolumn{3}{|l|}{ Sigarayı bırakma için en geçerli sebep nedir? } \\
\hline Sağlık sorunları & 77.6 & 76.1 \\
\hline Aile ve çevre baskısı & 6.1 & 7.1 \\
\hline Ekonomik nedenler & 12.2 & 6.5 \\
\hline Sigara yasakları & 2.0 & 3.8 \\
\hline \multirow[t]{2}{*}{ Diğer } & 2.0 & 6.5 \\
\hline & \multicolumn{2}{|c|}{$\left(p>0.05, x^{2}: 5.77, d f: 4\right)$} \\
\hline \multicolumn{3}{|c|}{ Sigarayı bırakmak için profesyonel yardım (sigara bırakma polikliniği vb.) almak gerekir mi? } \\
\hline Evet & 45.8 & 74.7 \\
\hline \multirow[t]{2}{*}{ Hayır } & 54.2 & 25.3 \\
\hline & \multicolumn{2}{|c|}{$\left(p=0.0001 ; x^{2}: 23.21 ; d f: 1\right)$} \\
\hline \multicolumn{3}{|l|}{ Sigara yasaklarının oluşturulmasının temel nedeni nedir? } \\
\hline Pasif içiciliğin sigara içmeyen çok sayıda insanda ciddi sağlık sorunları yaratmasıdır. & 75.5 & 84.4 \\
\hline Sigara içenleri ikinci sınıf hissettirmektir. & 6.1 & 4.3 \\
\hline Sigarayla ilişkili sağlık masraflarını azaltmaktır. & 4.1 & 4.8 \\
\hline İnsanların yaşam şekillerine müdahale etmektir. & 4.1 & 3.8 \\
\hline \multirow[t]{2}{*}{ Sadece Avrupa ile uyum amacıyla yapılan uygulamalardır. } & 10.2 & 2.7 \\
\hline & \multicolumn{2}{|c|}{$\left(p>0.05 ; x^{2}: 8.01 ; d f: 4\right)$} \\
\hline \multicolumn{3}{|c|}{ Okulunuzun içinde sigara yasaklarının düzgün bir biçimde uygulandığını düşünüyor musunuz? } \\
\hline Evet & 89.7 & 74.5 \\
\hline \multirow[t]{2}{*}{ Hayır } & 10.3 & 25.5 \\
\hline & \multicolumn{2}{|c|}{$\left(p=0.002 ; x^{2}: 9.178 ; d f: 1\right)$} \\
\hline \multicolumn{3}{|c|}{ Evinizin içinde sigara içiliyor mu, içilmiyorsa içen misafirlerinizin içmelerine izin veriyor musunuz? } \\
\hline Kesinlikle evimin içinde sigara içilmiyor & 37.8 & 44.3 \\
\hline Büyüklerimiz hariç kimseye sigara içirmiyorum & 5.1 & 6.3 \\
\hline Biz içmiyoruz, ama içenlere izin veriyoruz & 13.3 & 17.2 \\
\hline İçiliyor & 42.9 & 24 \\
\hline \multirow[t]{2}{*}{ Biz istemesek bile misafirler içiyor } & 1.0 & 8.3 \\
\hline & \multicolumn{2}{|c|}{$\left(p=0.005 ; x^{2}: 14.986 ; d f: 4\right)$} \\
\hline
\end{tabular}

Katılımcıların \%81.3'ü "sigara yasaklarının oluşturulmasının temel nedenleri” ile ilgili soruyu pasif içiciliğin yaratığı sağlık sorunları olarak ifade etmiştir. Bu soruya yönelik olarak kullanımı olan ve olmayanların görüşlerinin farklı olmadığı görülmüştür ( $p>0.05)$. Kullananların \%75.5'i, kullanmayanların \%84.4'ü pasif içiciliğin yarattığı sorunları öncelikli belirtmiştir. Her iki grubun da sigara yasaklarının, sigara içenleri ikinci sınıf vatandaş olarak hissettirmek, sigarayla ilgili sağlık masraflarını azaltmak, insanların yaşam şekillerine müdahale etmek amacıyla oluşturulduğuna ilişkin görüşleri de yüzde olarak yakın bulunmuştur (Tablo-2). 
Araştırmada, okulun içinde sigara yasaklarının uygulanması konusunda sigara kullanımı olan ve olmayanların farklı görüşlere sahip oldukları saptanmıştır. Sigara kullananların \%89.7'si, kullanmayanların \%74.5’i okulda sigara yasaklarının düzgün bir biçimde uygulandığını belirtmiştir $(p=0.002)$. Çalışmamızda, evde sigara içilmesi konusundaki tutumların da sigara kullanımı olan ve olmayanlara göre farklılaştığı bulunmuştur $(p=0.005)$. Sigara kullanımı olanların \%42.9'u evinde sigara içildiği; kullanımı olmayanların \%55.8'i evin bireyleri ya da gelen misafirler tarafından sigara dumanına maruz kaldığı saptanmıştır (Tablo-2).

\section{Tartışma}

Araştırmamızda polis okulu öğrencilerinde sigara içme sıklığı \%33.7 olarak bulunmuştur. Bu araştırmada, polis okulu öğrencilerinin sigara içme oranlarının ülkemizde gençler arasında yapılan diğer çalışmalara $(14,15)$ göre son yıllarda paralellik gösterdiği görülmektedir. Türkiye'de aynı yaş grubunda bulunan diğer üniversitelerde yapılan çalışmalarda da yakın sonuçlar elde edilmiştir. 2009 yılında, 9 üniversitede gerçekleştirilen bir araştırmada, üniversite 1.sınıf erkek öğrencilerinin sigara kullanımı \%32 (7), 2013 yılında Ege Üniversitesi öğrencilerine yönelik yapılan bir diğer çalışmada erkek öğrencilerde kullanım oranı \%33.6 olarak bulunmuştur (16). 2001 yılında Elazığ'da polis öğrencilerine yönelik yapılan bir araştırmada öğrencilerin \%66.6'sı sigara içtiğini belirtmiştir. Bu durum polis okulu öğrencilerinin yaşlarının büyük olması (23-29 yaş arası) nedeniyle içme oranlarının Türk erişkin popülasyonuna benzer şekilde yüksek olmasından kaynaklanmış olabilir (13).

Yetişkin polislerin sigara ve alkol kullanımlarına yönelik yapılan çalışmalarda, sigara kullanım oranlarının normal popülasyona göre daha yüksek olduğu ortaya çıkmıştır. 1995-1999 yıllarında, ülke çapında değişik meslek gruplarından 12.500 kişiye yapılan araştırmada sigara kullanım oranı polislerde \%64.7, şoförlerde \%74.3, öğretmenlerde \%48.6, sanatçılarda \%46.2, doktorlarda \%43.1, sporcularda \%34.9 olarak saptanmıştır (8). Elazığ'da emniyet teşkilatına yönelik yapılan bir araştırmada polis memurlarının \%61.8'i (12), Konya'da yapılan bir diğer araştırmada polislerin \%41.9'u sigara kullandığı beyan etmiştir (11). Aynı yıllarda farklı meslek gruplarına yönelik yapılan diğer çalışmalar değerlendirildiğinde; öğretmenlerde sigara içme yaygınlığı daha düşük bulunmuştur $(17,18)$. Bu durum polislik mesleğinin sigara kullanımı açısından risk oluşturduğunu göstermektedir.

Son yıllarda polis okullarında sigara kullanımının azaldığı gözlenmektedir. Bu değişimde sigara kullanımının önlenmesine yönelik yapılan hukuksal düzenlemelerin etkili olduğu düşünülebilir. 2008 yılında 4207 sayılı kanun kapsamında, kamu kurum ve kuruluşları, toplu taşıma araçları, restoran vb. işletmelerin tüm kapalı alanlarda sigara kullanımı yasaklanmıştır (4207 sayılı kanun). Bu değişiklik sonrasında, ülkemizde erişkinler arasında da tütün kullanımının azaldığı görülmektedir. Küresel Yetişkin Tütün Araştırmasının sonuçlarına göre Türkiye'de erkeklerde tütün kullanımı 2008 yılında \%47.9 iken 2012 yılında \%41.4'e düşmüştür. Erişkinlerde 15 yaşın üzerinde tütün kullanmayı bırakmayı isteme 2008 yılında \%27.8 iken 2012 yılında \%35.4'e çıkmıştır (3). Sağlık Bakanlığı'nın sigarayı bırakmaya yönelik yapmış olduğu politikaların ve uygulamaların (Alo-171 Sigara Bırakma Hattı, ücretsiz ilaç desteği) da bu değişimde etkili olduğu düşünülmektedir. Bunun yanısıra sigarayla mücadele Türkiye'deki bazı okulların yapmış olduğu önleyici, bilinçlendirici politikaların, projeler ve kampanyaların etkili olduğu da bir diğer gerçektir. Elazığ'da Polis okulunda "sigarayı bırak ve kazan" kampanyasına sigara içen öğrencilerin \% 45.1'i katılmış ve kampanya sonunda başarı oranı \%14.3 olarak bulunmuştur (19). Bu durum polis okullarının sigara kullanımına yönelik mücadelesinin bir sonucudur.

Son yıllarda sigaraya başlama yaşının gittikçe düştüğü gözlemlenmektedir. DSÖ'nün yaptığı bir araştırmaya göre; özellikle gelişmekte olan ülkelerde sigaraya genellikle 19 yaşından önce başlanmakta ve bağımlılık bu yaşa kadar yerleşmektedir, bu nedenle de önleme çalışmalarının ergenlik döneminde yapılması önemlidir $(9,20)$. Çalışmamızda sigaraya başlama yaşı en yaygın olarak 16-19 yaş grubunda bulunmuştur; fakat kullanımın 7 yaşın altına indiği de görülmüştür. Bu sonuç, Konya'da polislere yönelik yapılan bir diğer araştırma ile paralellik göstermektedir (11).

Araştırmamızda, öğrencilere, sigara kullanımına başlama nedenleri sorulmuş ve sigara kullanımı olan ve olmayanların bu konuda farklı görüşlere sahip oldukları gözlemlenmiştir. Özellikle sigara kullananların sigaranın rahatlatıcı etkisi ve içmeden yapamamak gibi yoksunluk belirtilerini daha yaygın olarak vurguladıkları görülmektedir. Kullanmayanların \%41.3'ü sigara kullanım nedenini arkadaşlar arasında ilgi çekmek olarak ifade ederken sigara kullanan hiçbir bireyin bu seçeneği seçmemesi önemli bir bulgudur. Bu durum, sigara yönelik görüşlerin kullanan ve kullanmayan açısından ne kadar farklı olduğunun göstergesidir. Sigara kullanıcıları sigaranın insan fizyolojisinde yarattığı bağımlılık yapıcı etkilerinden ötürü sigarayı tercih ederlerken, kullanmayanlar sigara kullanımının sosyal yönüne dikkat çekmektedir.

Literatüre göre sigara bağımlılarının dörtte üçü sigarayı bırakmak istemekte, üçte biri ise en az üç ciddi bırakma girişiminde bulunmaktadır. Sigarayı kendi başına bırakmak oldukça zor olup bu şekilde bırakabilme oranı $\% 4$ iken, profesyonel yardım aracılığı ile bu oran \%45'e çıkabilmektedir (5). Araştırmamızda sigarayı bırakmada profesyonel yardım almak konusunda sigarayı kullanan (\%45.8) ve kullanmayanların (\%74.7) farklı görüşlere sahip olduğu bulunmuştur. Bağımlılık tedavisinde 
öncelikle kişinin bırakma konusunda hazır olması, motive olması en önemli adımdır. Ögel'e göre bağımlılık tedavisinde kullanıcıların değişmek için verdikleri kararlar ve sözler zaman içinde değişebilmektedir. Bu çatışma ve bocalamanın ardındaki neden, bağımlılıktan vazgeçme isteksizliği ve maddeyi bırakma korkusu da olabilir (21). Bu nedenledir ki sigarayı bırakma, birinci derecede kişinin kendi kararı, isteği ve iradesiyle ilişkilidir. Hekimlerin bu konudaki rolü, sigaranın zararları ve bırakma yöntemleri konusunda bilgilendirici, özendirici ve destekleyici olmak, ortaya çıkan fiziksel ve ruhsal yoksunluk belirtilerini ortadan kaldırmaya yönelik gerekli tıbbi yardımda bulunmak ve bırakma eyleminin devamını sağlamak için bireyi desteklemektir (22).

Araştırmamızda hem sigara kullanan ve hem de kullanmayanlar sigarayı bırakmak konusunda en önemli neden olarak sağlık sorunlarını (\%76.8) vurgulanmıştır. Son yıllarda sigarayı bırakmak konusunda geliştirilen sağlık politikaları ve önleme çalışmaları toplumun sigaranın sağlığa zararlı olduğu gerçeğini kabul etmesini sağlamıştır. Lise öğrencilerine yönelik yapılan bir araştırmada, öğrencilerin \%95.5'inin sigaranın sağlığa zararlı olduğu, \%81.9'unun sağlık üzerine olumsuz etkilerinin olduğunu, \%95.8'inin akciğer kanseri ile ilişkili olduğunu bildikleri ortaya konmuştur (23).

Günümüzde pasif içicilik, önemle üzerinde durulan diğer unsurlardan biri olmuştur. Yapılan bir araştırmada, lise öğrencilerinin \%82.4'ünün pasif sigara içiminin de sağlık üzerinde olumsuz etkileri olduğunu bildiği görülmüştür (23). Çünkü aktif sigara içimine bağlı birçok zararlı etkinin pasif sigara maruziyetine bağlı olarak da ortaya çıkabileceği artık bilinmektedir. Çevresel sigara dumanına pasif maruziyet akciğer kanseri ve kalp hastalıkları riskini artırmaktadır (2,24). Araştırmamızda kullanımı olmayanların \%55.8'inin evde pasif içici konumun olduğu bulunmuştur. Denizli'de yapılan bir araştırmada da sigara içmeyen kadınların \%47.6'sının, erkeklerin \%16.3'ünün evinde pasif olarak sigara dumanına maruz kaldığı sonucuna ulaşılmıştır (2). 2006 yılında 188 öğrenciye yönelik pasif etkilenim konusunun değerlendirildiği bir çalışmada, evde sigara tüketilmesi konusunda öğrencilerin anne ve babalarının beyanı öğrenilerek öğrencilerin idrar kotinin düzeylerini ölçülmüştür (8). Anne-baba ifadelerine göre çocukların \%72.3'ü sigara içilen evlerde yaşamaktadır ve bu evlerin \%34.6'sında evlerde her gün sigara içilmektedir. İdrar kotinin düzeyi sınırı $10 \mathrm{ng} / \mathrm{mL}$ olarak alındığı zaman çocukların \%76'sının sigara dumanından etkilendiği ortaya çıkmıştır (8).

Araştırmanın yalnızca ankete dayalı yapılması araştırmanın sınırıııklarındandır. İleriki çalışmalarda sözlü beyana dayalı bireysel görüşmelerin yapılandırılması ve sigara kullanımının karbonmonoksit ölçümleriyle değerlendirilmesinin çalışma sonuçlarındaki güvenilirliği artıracaktır.

\section{Sonuç}

Araştırmamızda polis okulu öğrencilerinde sigara kullanım yaygınlığının farklı üniversitelerde yapılan çalışmamalarla paralellik gösterdiği ve 2008 yılı öncesi polis okullarına yönelik yapılan araştırma sonuçlarına göre son yıllarda kullanım sıklığının azaldığı görülmektedir. Bu aşamada polis okullarının düzenlemiş olduğu sosyal projelerin ve 2008 yılından sonra yapılan hukuksal düzenlemelerin etkili olduğu düşünülmektedir.

Araştırmamızda sigara kullanımı olan ve olmayanların, insanların sigaraya başlama nedenleri, sigarayı bırakmada profesyonel yardım almanın gerekliliği ve sigara yasakları konusundaki görüşlerinin farklılık taşıdığı ortaya konmuştur. Sigara kullanımına yönelik yapılan görüş, tutum ve davranış araştırmaları, kullanımı olan ve olmayanların farklılıkları göz önünde bulundurularak planlanmalıdır.

Sigara kullanımı açısından risk grubu altında olan polislerin mesleklerinin yaratmış olduğu stres faktörlerinin düzenlenmesi ve sağlıklı çalışma koşullarının oluşturulması önemlidir. Sigara kullanımının önlenmesine yönelik yapılan hukuksal düzenlemelerin ve sağlık politikalarının gerek polislerde gerekse toplumun genelinde kullanımın azaltılmasında ve bırakmaya yönelik girişimlerin artmasında olumlu sonuçlar doğurduğu görülmektedir. Sigara kullanım yaşının düşmekte olması nedeniyle sigara kullanımını engellemeye yönelik eğitimlerin ve toplumu bilinçlendirme çalışmalarının arttıııması önem taşımaktadır.

\section{Kaynaklar}

1. Nakajima H. Message from the Director General of World Health Organisation for world no tobacco day. WHO Tobacco Alert. Internet Edition-Advisory Kit 1996;4:50-1.

2. Başer S, Hacıoğlu M, Evyapan F, Özkurt S, Kıter G, Zencir M. Denizli İ Merkezinde Yaşayan Erişkinlerin Sigara İçme Özellikleri. Türk Toraks Dergisi 2007;8(3):179-84.

3. Türkiye İstatistik Kurumu Başkanlığı, Küresel Yetişkin Tütün Araştırması Türkiye Raporu 2012. www.tuik.gov.tr (Erişim tarihi: 31.08.2012).

4. Aslan D, Şahin A. Sigara ile mücadele konusunda yapılmış bir çalışmada kullanılan akran danışmanlığı yöntemi ile ilgili kısa bir rapor. Hacettepe Toplum Hekimliği Bülteni 2003;24(2):11-2.

5. Çakmak D, Evren C. Alkol ve Madde Kullanım Bozuklukları. İstanbul: Özgül Matbaacılık; 2006;102-4.

6. Tanter RE, Sambrano S, Dunn MG. Predictive variables by developmental stages: A center for substance abuse. Prevention Multisite Study, Psychol Addict Behav 2002;16(4 Suppl):S3-10. 
7. Özcebe H, Güçiz Doğan B, İnal E, Haznedaroğlu D, Bertan M. Üniversite öğrencilerinin sigara içme davranışları ve ilişkili sosyodemografik özellikler. Türk Toraks Dergisi 2014;15(1):42-8.

8. T.C. Temel Sağlık Hizmetleri Genel Müdürlüğü. Küresel Yetişkin Tütün Araştırması Türkiye Raporu 2010. Ankara: Anıl Matbacilı; 2010:37-75.

9. World Health Organization. The tobacco atlas. [cited 01 June 2012] http://www.who.int/tobacco/statistics/tobacco_atlas/en/.

10. Kutlu R, Çivi S, Karaoğlu O. The relationship between the frequency of smoking and depression among police officers. TAF Prev Med Bull 2008;7(1):31-8.

11. Richmond RI, Wodak A, Kehoe L, Heather N. How healthy are the police? A survey of life-style factors. Addiction 1998;93(11):1729-37.

12. Deveci SE, Güler H, Deveci F, Açık Y, Muz MH. Elazığ emniyet teşkilatı personelinin sigara içme davranışları, bağımlıık düzeyleri ve sigara-sağlık ilişkisine yaklaşımları. Solunum Hastalıkları 2005;16(1):12-7.

13. Açık Y, Polat SA, Deveci E. Bir polis okulu öğrencilerinde sigara kullanım sıkığı araştırması. AÜTD 2001;33(1):23-7.

14. Hasim TJ. Smoking habits of students in college of applied medical science. Saudi Med J 2000;21(1):76-80.

15. Onal AE, Tumerdem Y, Ozel S. Smoking addiction among university students in Istanbul. Addict Biol 2002;7(4):397-402.

16. Havaçeliği D. Partner ilişkilerindeki ilişki bağımlılı̆ının ebeveyn bağlanma biçimleri ve madde kullanımı ile ilişkisi. Ege Üniversitesi Sağlık Bilimleri Yüksek Lisans Tezi 2013.

17. Marakoğlu K, Erdem D, Çivi S. Konya'da ilköğretim okullarındaki öğretmenler arasında sigara içme durumu. Türk Toraks Dergisi 2007;8(1):37-40

18. Çoban SA, Sungur G. Öğretmenlerin sigara kullanım konusundaki davranışları ve görüşleri. Türk Toraks Dergisi 2013;14(2):98102.

19. Açık Y, Gülbayrak C, Deveci E, Ozan T. Elazığ Polis Okulu'nda düzenlenen "sigarayı bırak kazan" kampanyasına katılan öğrencilerin başarı durumları. Fırat Tıp Dergisi 2002;7(3):823-7.

20. Dabak Ş. Sigara ve sağlık. In: Tür A (editör). Sigaranın Bilimsel Yüzü. İstanbul: Logos Yayıncılık; 2004:1-32.

21. Ögel K. Sigara, alkol ve madde kullanım bozuklukları: Tanı, tedavi ve önleme. İstanbul: Yeniden Yayınları; 2010:7-9

22. Yorgancioglu A, Esen A. Cigarette dependence and physicinas. Turkish Thoracic J 2000;1(2):90-5.

23. Çelik $P$, Ayşen E, Yorgancıoğlu A, Şen SF, Topçu F. Manisa ilinde lise öğrencilerinin sigaraya karşı tutumları. Türk Toraks Dergisi 2000;1(1):61-6.

24. Karlıkaya C, Öztuna F, Solak ZA, Özkan M, Örsel O. Tütün kontrolü. Türk Toraks Dergisi 2006;7(1):51-64. 